\title{
Aplicación de Convenios Internacionales en materia de familia y su acople con fenómenos contemporáneos ${ }^{\star}$
}

\author{
Verónica Valenzuela Muñoz ${ }^{\star *}$
}

\begin{abstract}
Existen al menos dos Convenios Internacionales asociados a la Justicia de Familia que han sido suscritos y ratificados por Chile, por tanto, ley de la República, que operan desde hace años en una aparente opacidad. La complejización del sistema social ha obligado a la visibilización de dichos Convenios, especialmente ante fenómenos tales como los movimientos migratorios y la constitución de familias con características de transnacionalidad. La ejecución en Chile del "Convenio de Nueva York de 1956 para la Obtención de Alimentos en el Extranjero" y el "Convenio de La Haya de 1980 sobre los Aspectos Civiles de la Sustracción de Niños, Niñas y Adolescentes", tras los fenómenos enunciados, han permitido la observación de algunas prácticas asociadas a los géneros, las edades y la paternidad/ maternidad, distinciones que intentaremos develar en el presente artículo.
\end{abstract}

Palabras clave: Convenios Internacionales, Familias Transnacionales, Migraciones.

\section{Aplicação de Convênios Internacionais em matéria de Família e seu envolvimento com fenômenos contemporâneos}

\section{RESUMO}

Há pelo menos dois Acordos Internacionais relacionados com a Justiça de Família que tem sido assinados e ratificados pelo Chile, portanto, lei da República, que operam há anos numa opacidade aparente. A complexidade do sistema social tem forçado a visibilidade de ditos Convênios, especialmente

* Ponencia expuesta en el II Congreso Nacional de Investigación en Trabajo Social, realizado el 5 y 6 de noviembre de 2014, en la Universidad Católica Silva Henríquez. Respecto al estilo narrativo, el idioma castellano no facilita un articulado común para referir a ambos géneros, explicitándose así que al referir a niños o hijos, se hace referencia a niños y niñas, hijos e hijas, lo mismo respecto de otros conceptos que permiten tal distinción.

** Chilena, Trabajadora Social Área Social - Oficina Internacional Corporación de Asistencia Judicial R.M. E-mail: vivalenzuela@cajmetro.cl 
a fenômenos como a migração e a constituição de famílias com caraterísticas da transnacionalidade. A execução no Chile do "Convênio de Nova Iorque de 1956 para a obtenção de alimentos no Exterior" e "a Convenção da Haya de 1980 sobre os Aspectos Civis do Rapto de Crianças e Adolescentes”, após dos fenômenos enunciados, têm permitido a observação de algumas práticas associadas aos gêneros, as idades e a paternidade / maternidade, distinções que tentam-se revelar no presente artigo.

Palavras-chave: Convênios Internacionais, Famílias Transnacionais, Migrações.

\title{
Application of International Conventions related to family issues and their link to contemporary phenomena.
}

\author{
ABSTRACT
}

\begin{abstract}
There are at least two international conventions associated with Family Law that have been signed and ratified by Chile, which have been operating for years in apparent opacity.

The complexity of the social system has forced the visibility of those Conventions, especially in connection with migration and the formation of transnational families.

The implementation in Chile of the "Convention on the Recovery Abroad of Maintenance, New York 20 June 1956" and "Convention of 25 October 1980 on the Civil Aspects of International Child Abduction", based on the aforementioned phenomena, have allowed the observation of some practices associated with gender, age and paternity/maternity, which we will discuss in this article.
\end{abstract}

Keywords: International Conventions, Transnational Families, Migrations.

\section{Contexto chileno para la aplicación de Convenios Internacionales en materia de Justicia de Familia}

En términos de acceso a la Justicia, las últimas reformas legales emprendidas por Chile -especialmente en materias de Justicia de Familia, Penal y Laboral, cuyos procesos judiciales, además de ser muchos de ellos públicos y transparentes, resultan bastante expeditos en su tramitación si se les compara con el resto de países de la Región-, ubican al país en los primeros lugares respecto a diversas mediciones efectuadas por el Observatorio Iberoamericano de Justicia que mantiene la Conferencia de Ministros de Justicia de los Países Iberoamericanos (COMJIB). En su último informe, dicho organismo, en la línea acceso a la justicia y respecto de "Es- 
tadísticas e Indicadores Armonizados de los Sistemas de Justicia en América Latina" (2012), sitúa a Chile en los primeros lugares respecto de diversas dimensiones.

En ese sentido, destaca la inclusión de medios tecnológicos disponibles para todos/as los/as usuarios/as del sistema judicial chileno y desde cualquier lugar, condición desde la cual se intenta garantizar el derecho al acceso de la información, situando a Chile en los primeros lugares respecto del indicador "Acceso a la información a través de Internet", pasando desde el $10^{\circ}$ lugar el año 2008, al $1^{\circ}$ lugar el año 2009, ocupando desde el año 2010 el $2^{\circ}$ lugar en torno a esta categoría.

Junto a los logros en términos de acceso al sistema de justicia, el país ha logrado avanzar en la entrega de asesoría jurídica gratuita, que permite a conglomerados carentes de recursos económicos, la contratación de un abogado que los represente ante un eventual litigio. La asesoría jurídica gratuita en materias de Derecho de Familia de conglomerados en situación de vulneración y/o exclusión social, tradicionalmente ha sido una responsabilidad de las 4 Corporaciones de Asistencia Judicial ${ }^{1}$, las que en su conjunto otorgan cobertura a nivel nacional a cualquier residente en el país, independiente de su nacionalidad y situación migratoria.

Es un servicio público, descentralizado y sin fines de lucro, cuya misión es proporcionar orientación y asesoría jurídica a todas las personas que así lo requieran, y patrocinar judicialmente de manera profesional y gratuita a quienes no cuenten con los recursos para hacerlo (...) La labor de esta institución contribuye al principio fundamental de toda democracia: la igualdad ante la ley y la justicia. Corporación de Asistencia

Corporación de Asistencia Judicial de la Región Metropolitana cuya cobertura territorial refiere a las regiones Metropolitana, O’Higgins, del Maule y Magallanes; la Corporación de Asistencia Judicial de Valparaíso con cobertura respecto las regiones de Atacama, Coquimbo y Valparaíso; la Corporación de Asistencia Judicial de Tarapacá para las regiones de Tarapacá y Antofagasta; y la Corporación de Asistencia Judicial del Biobío respecto las regiones del Biobío, La Araucanía, Los Lagos, Los Ríos y Aysén. 
Judicial R.M. 2015 [en línea] http://www.cajmetro.cl/presentacion/ [consulta: 05 agosto 2015]

Contrariamente a estos logros alcanzados, continúan aún ejecutándose desde una aparente opacidad algunos Convenios Internacionales ratificados por Chile en materia de familia e infancia, los que, observados en contextos de migración y conformación de familias reconstituidas, hacen necesario el revelar este tipo de intervenciones por cuanto favorecen la inclusión social.

\section{Convenios Internacionales en materia de familia e infancia suscritos y ratificados por Chile}

El año 1961 el Estado de Chile suscribe y ratifica el Convenio de Naciones Unidas sobre la Obtención de Alimentos en el Extranjero efectuado el 20 de junio del año 1956, en adelante "Convenio de Nueva York". Dicho pacto se propone la obtención de alimentos cuando el alimentante [hijo/a-niño/a] y alimentario (frecuentemente el padre [hombre]) se encuentran en Estados/países diferentes y partícipes de dicho Convenio. Subyace la idea que existe una distancia geográfica y/o espacial relevante entre las partes, así por ejemplo, entre padre e hijo.

Su organismo ejecutor corresponde a las Corporaciones de Asistencia Judicial (CAJ), las que a través de su Oficina Internacional -en tanto organismo central de ejecución- asumen finalmente el rol de "Autoridad Remitente" (cuando la solicitud emana desde Chile hacia el extranjero) y/o de "Institución Intermediaria" (respecto de solicitudes recepcionadas desde el extranjero para su judicialización en Chile), roles que han sido indicados en el Convenio.

Por otro lado, en 1994 el Estado de Chile suscribe y ratifica el Convenio de La Haya de 1980 sobre los Aspectos Civiles de la Sustracción de Niños, en adelante "Convenio de La Haya", cuyo propósito es garantizar la restitución inmediata de niños trasladados y/o retenidos en forma ilícita desde cualquier Estado parte del Convenio, velando además por proteger que los derechos de custodia (cuidado personal) y visitas (régimen comunicacional), vigentes 
en los Estados contratantes, sean respetados por los demás Estados partícipes del Convenio. En este punto, el rol que asumen las CAJ y específicamente la Oficina Internacional, quien finalmente concentra las solicitudes desde y hacia el extranjero, es el de "Autoridad Central" tal como lo indica el propio Convenio. Junto con lo expuesto, el "Convenio de La Haya" integra como posibilidad las solicitudes de visitas internacionales de parte de alguno de los padres, es decir, de quien no reside junto al niño/a.

$\mathrm{Al}$ realizar un cruce entre las diversas nomenclaturas o roles que adquiere la institucionalidad en la aplicación de ambos Convenios Internacionales y para facilitar la comprensión respecto cómo éstos operan, es posible observar la siguiente figura:

Figura 1: Roles que asume el organismo ejecutor respecto de ambos Convenios Internacionales dependiendo si la solicitud emana desde el propio Estado/país o si proviene desde el extranjero. Fuente: Elaboración propia.

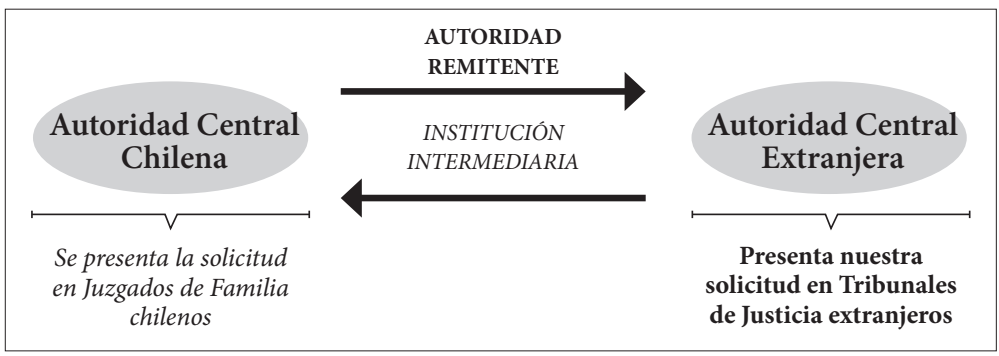

En cursiva se han indicado las actuaciones asociadas a peticiones que provienen desde el extranjero y que, por lo tanto, se materializan en Chile por el organismo ejecutor, sea como "Autoridad Central" si se trata de un caso de sustracción o visitas internacionales, o como "Institución Intermediaria" si la petición refiere a pensión alimenticia.

Se han indicado en negritas las peticiones que emanan desde Chile hacia el extranjero, siendo recepcionadas por la "Autoridad Central o Institución Intermediaria" -dependiendo de la materia en cuestión- correspondiente al otro Estado, quien finalmente llevará dicha solicitud ante la Justicia de dicho país para su resolución. 


\section{Convención Internacional por los Derechos del Niño (CIDN) y su integración respecto otros Convenios Internacionales en materia de familia e infancia}

La Convención Internacional por los Derechos del Niño, aprobada por la Asamblea General de las Naciones Unidas el 20 de noviembre de 1989 y ratificada por Chile en 1990, integra -en cuanto cuerpo legal- diversos tratados, pactos y convenios asociados a la infancia y niñez, situación de la cual no se excluyen los Convenios de Nueva York y de La Haya, los que en su esencia son posibles de identificar en la propia Convención a través del siguiente paralelo:

Figura 2: Paralelo entre CIDN y Convenio de Nueva York y de La Haya. Fuente: elaboración propia.

Convención Internacional por los Derechos
del Niño de 1989
Artículo 9
l. Los Estados Partes velarán porque el niño no sea
separado de sus padres contra la voluntad de éstos,
excepto cuando, a reserva de revisión judicial, las
autoridades competentes determinen, de confor-
midad con la ley y los procedimientos aplicables,
que tal separación es necesaria en el interés supe-
rior del niño. Tal determinación puede ser necesa-
ria en casos particulares, por ejemplo, en los casos
en que el niño sea objeto de maltrato o descuido
por parte de sus padres o cuando éstos viven se-
parados y debe adoptarse una decisión acerca del
lugar de residencia del niño.
2. En cualquier procedimiento entablado de con-
formidad con el párrafo 1 del presente artículo,
se ofrecerá a todas las partes interesadas la opor-
tunidad de participar en él y de dar a conocer sus
opiniones.
3. Los Estados Partes respetarán el derecho del ni-
ño que esté separado de uno o de ambos padres a
mantener relaciones personales y contacto directo
con ambos padres de modo regular, salvo si ello es
contrario al interés superior del niño.

Convenio de La Haya de 1980

Derecho de visitas (comunicación directa y regular) [Entorno habitual, país de residencia] 


\begin{tabular}{|c|c|c|}
\hline $\begin{array}{l}\text { Artículo } 10 \\
\text { 1. De conformidad con la obligación que incum- } \\
\text { be a los Estados Partes a tenor de lo dispuesto en } \\
\text { el párrafo } 1 \text { del artículo 9, toda solicitud hecha } \\
\text { por un niño o por sus padres para entrar en un } \\
\text { Estado Parte o para salir de él a los efectos de la } \\
\text { reunión de la familia será atendida por los Es- } \\
\text { tados Partes de manera positiva, humanitaria y } \\
\text { expeditiva. Los Estados Partes garantizarán, ade- } \\
\text { más, que la presentación de tal petición no traerá } \\
\text { consecuencias desfavorables para los peticiona- } \\
\text { rios ni para sus familiares. } \\
\text { 2. El niño cuyos padres residan en Estados di- } \\
\text { ferentes tendrá derecho a mantener periódica- } \\
\text { mente, salvo en circunstancias excepcionales, } \\
\text { relaciones personales y contactos directos con } \\
\text { ambos padres. Con tal fin, y de conformidad con } \\
\text { la obligación asumida por los Estados Partes en } \\
\text { virtud del párrafo } 1 \text { del artículo 9, los Estados } \\
\text { Partes respetarán el derecho del niño y de sus } \\
\text { padres a salir de cualquier país, incluido el pro- } \\
\text { pio, y de entrar en su propio país. El derecho de } \\
\text { salir de cualquier país estará sujeto solamente a } \\
\text { las restricciones estipuladas por ley y que sean } \\
\text { necesarias para proteger la seguridad nacional, } \\
\text { el orden público, la salud o la moral pública o } \\
\text { los derechos y libertades de otras personas y que } \\
\text { estén en consonancia con los demás derechos re- } \\
\text { conocidos por la presente Convención. }\end{array}$ & & $\begin{array}{l}\text { Convenio de La Ha- } \\
\text { ya de } 1980 \\
\text { Derecho de visitas } \\
\text { (comunicación di- } \\
\text { recta y regular) }\end{array}$ \\
\hline $\begin{array}{l}\text { Artículo } 11 \\
\text { 1. Los Estados Partes adoptarán medidas pa- } \\
\text { ra luchar contra los traslados ilícitos de niños } \\
\text { al extranjero y la retención ilícita de niños en el } \\
\text { extranjero. } \\
\text { 2. Para este fin, los Estados Partes promoverán la } \\
\text { concertación de acuerdos bilaterales o multilate- } \\
\text { rales o la adhesión a acuerdos existentes. }\end{array}$ & & $\begin{array}{l}\text { Convenio de La Ha- } \\
\text { ya de } 1980 \\
\text { NO a la retención } \\
\text { ilícita } \\
\text { NO al traslado ilícito }\end{array}$ \\
\hline
\end{tabular}




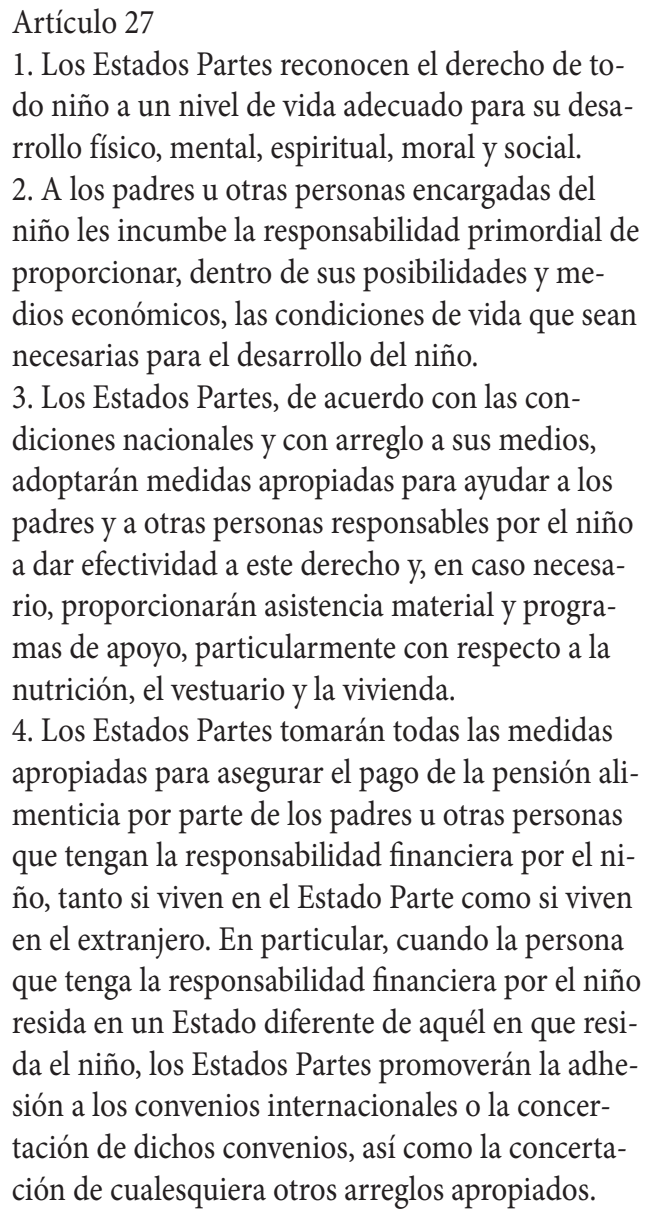

\section{Convenios de Nueva York de 1956 y de La Haya de 1980: complejidades en la aplicación desde la perspectiva de las edades, los géneros y las parentalidades}

\section{Desde las perspectivas de las edades: Infancia y Niñez, conglomerados sin acceso directo a la ejecución de los Convenios Internacionales}

Los Convenios de Nueva York y de La Haya intentan garantizar algunos derechos de la infancia y niñez, en este caso, que niños y niñas cuenten con los recursos económicos de parte de sus padres 
para la satisfacción de sus necesidades y garantizar así su desarrollo, además de resguardar que no sean trasladados y/o retenidos por alguno de ellos en otro país/Estado distinto al de su residencia habitual. Pese a ello, niños y niñas no acceden en forma directa a los Convenios referidos.

Tal indicación resulta paradójica por cuanto, a pesar del reconocimiento y garantía de estos derechos, ambos Convenios Internacionales no constituyen herramientas disponibles directamente para este conglomerado social. Desde un punto de vista legal, niños y adolescentes (así menores de 18 años) son concebidos como "incapaces", por lo tanto, pese a ser sujetos de derecho, para cualquier actuación legal requieren de un representante que actúe en su nombre. En principio, se comprende como representantes legales a los padres o a quien se responsabilice de su cuidado y protección residiendo junto al él. ${ }^{3}$

Junto con lo anterior, la actual organización social de tipo adultocéntrica que privilegia la perspectiva de los adultos por sobre otros grupos sociales, favoreciendo así la asimetría en las interacciones, es otra limitante estructural para que niños y niñas accedan a estos mecanismos y posibilidades de ejercicio de derechos y ciudadanía en forma directa. Tales condiciones hacen que, de no existir una motivación o necesidad particular del representante

2 No gozan de capacidad “(...) el infante o niño todo el que no ha cumplido siete años; impúber, el varón que no ha cumplido catorce años y la mujer que no ha cumplido doce; [menor] adulto, el que ha dejado de ser impúber (...); y menor de edad, o simplemente menor, el que no ha llegado a cumplir los 18 años" (Código Civil, Art. 26, Biblioteca del Congreso Nacional, Código Civil [en línea] http://bcn.cl/1dua2 [consulta: 12 agosto 2015]).

3 Título preliminar. Art. 43. Son representantes legales de una persona el padre o la madre, el adoptante y su tutor o curador. Título X. Art. 245. Si los padres viven separados, la patria potestad será ejercida por aquel que tenga a su cargo el cuidado personal del hijo, de conformidad al artículo 225 (...) Título IX. Art. 225. Si los padres viven separados podrán determinar de común acuerdo que el cuidado personal de los hijos corresponda al padre, a la madre o a ambos en una forma compartida. El acuerdo se otorgará por escritura pública o acta extendida ante cualquier oficial del Registro Civil y deberá ser subinscrito al margen de la inscripción de nacimiento del hijo dentro de los treinta días subsiguientes a su otorgamiento (...) A falta de acuerdo del inciso primero, los hijos continuarán bajo el cuidado personal del padre o madre con quien estén conviviendo (Código Civil, Biblioteca del Congreso Nacional [en línea] http://bcn.cl/1dua2 [consulta: 05 agosto 2015]). 
legal del niño de solicitar se regule el aporte alimenticio del otro progenitor, o se intervenga para obtener la restitución de este a su país de residencia habitual, o se regule un régimen comunicacional (visitas), el respeto a la vigencia de estos derechos es algo que no resulta posible de aspirar por el propio niño afectado y/o vulnerado.

A partir de lo expuesto, se puede presumir una alta prevalencia de niños y niñas que, pese a vivenciar alguna situación vulneradora de derechos como ser sustraído de su entorno habitual, o no lograr vincularse directa y regularmente con alguno de sus padres, o no recibir apoyo económico de alguna de estas figuras, permanecen en la más absoluta invisibilidad, constituyendo una cifra negra respecto de la aplicación de los Convenios Internacionales de Nueva York y de La Haya.

\section{Desde la perspectiva de género y la parentalidad: "madres sustractoras" vs. "padres desvinculados"}

Al sistematizar la experiencia de intervención en relación con la aplicación de los Convenios Internacionales de Nueva York y de La Haya, es posible observar que frecuentemente y entrecruzado con el fenómeno migratorio, para el caso del Convenio de La Haya son las madres [mujeres] quienes sustraen a sus hijos a fin de trasladarlos en forma lícita o ilícita a otro Estado, para luego retenerlos en el lugar de destino y, de este modo, cambiar de país de residencia. Esta figura es frecuente de observar en familias cuyos padres se encuentran separados, siendo la madre quien se traslada junto al hijo a otro Estado/país y contextualizando dicha salida como "vacacional" o "para visitar a un familiar". Por su parte, el padre [hombre] debe autorizar dicha salida al extranjero en forma explícita en una notaría.

La madre sustractora, quien en definitiva lo que intenta es cambiar su país de residencia en compañía de su hijo, ya sea porque ese traslado implica retornar a su lugar de origen y/o terminar con una relación de pareja (la que muchas de ellas argumentan estar caracterizada por la violencia), estaría vulnerando los derechos de 
ese niño, quien además de no regresar a su país de residencia habitual, abandona vínculos afectivos que pudiesen ser relevantes para él: su padre, familia extensa, grupo de pares, escuela, en algunos casos algunos hermanos, además de gran parte de sus pertenencias, todo lo que se denomina su "centro de vida" y que lo configuran como una víctima de sustracción materna.

En ese sentido, es posible observar el relato de un padre [hombre] quien refiere al contexto en que se produce la sustracción de su hijo de 11 años:

(...) Siento que ella me engañó de la forma más desconsiderada al proponerme viajar a Perú sólo de vacaciones por 15 días con mi hijo menor. Como consta en la autorización de viaje que firmé, ella decidió vivir en Perú con su pareja y acordamos que los niños se quedarían conmigo en forma definitiva, por eso ella me había cedido la Tuición y Cuidado Personal de mis dos hijos (...) No se le ha puesto una pistola en el pecho para que ella firme, esto fue totalmente voluntario (...) El día en que mi hijo viajó fue el más triste de mi vida, porque lo vi por última vez de la peor manera, sufriendo y llorando porque él no quería viajar a Perú (...) Esto siempre fue estipulado, que mi hijo menor iba a volver conmigo después de sus vacaciones, pero al llegar la fecha de retorno, llamé para confirmar el regreso y hasta la fecha siempre he tenido varias versiones de la situación de mi hijo; que volverá en un mes, después a dos meses, y luego me confirmó que no me lo entregaría, ya que ella decidió quedarse con él definitivamente. En las conversaciones que tengo con mi hijo, él siempre me dice que quiere volver a Chile a vivir conmigo y su hermana, que su mamá le dijo que el próximo año volvería a Chile. Lo que quiere ella es separarnos como familia, ya que llevamos un fuerte lazo entre los tres. (Relato escrito entregado por un padre, usuario de la Oficina Internacional, 25 de agosto 2014).

La sustracción interparental es un fenómeno indicado en el estado del arte como "(...) el acto de robar, retener y ocultar a uno o a va- 
rios de los hijos e hijas o nietos y nietas, con el objetivo de privar a uno de los progenitores de su convivencia”. (Carrillo, 2011; 562). Los registros estadísticos que mantienen la Oficina Internacional, así como la Autoridad Central para la Aplicación del Convenio de La Haya de 1980, indican para el periodo comprendido entre los años 2011 y septiembre de 2014, y respecto de un total de 135 peticiones de restitución, que:

- Quienes accedieron a esta posibilidad en representación de sus hijos fueron padres en un 86\%, registrándose tan sólo un $14 \%$ de solicitantes madres.

- El número de peticiones provenientes desde el extranjero respecto de niños que estaban siendo retenidos ilícitamente en Chile alcanzó al 51\% de los casos.

- Por su parte, las peticiones derivadas desde Chile hacia otros Estados parte del Convenio de La Haya de 1980 alcanzan al $49 \%$ del total de casos (niños respecto de los cuales se solicita su restitución a nuestro país, en cuanto país de residencia habitual de ese niño).

- Perú es el Estado/país que concentra el mayor porcentaje de solicitudes desde y hacia el extranjero, con un $20 \%$ de casos de sustracción interparental respecto del total considerado.

Como contrapartida y asociado a la aplicación del Convenio de Nueva York, es posible observar que son los padres [hombres] quienes mayoritariamente cambian de país de residencia sin sus hijos, desvinculándose de ellos en lo económico y, en algunos casos, también en lo afectivo.

(...) Él me comentó que varios de sus amigos se habían ido a Alemania, España y otros países en busca de dinero y que les iba bien, que él quería hacer lo mismo, que nos vendría a buscar y esas cosas que se dicen sin pensar. Decide viajar aunque los niños están muy pequeños (uno de 13 años, otro de 7 años y el menor de 3 o 4 años). Esto fue en agosto del año 2001 cuando decide irse a "buscar un futuro para sus 
hijos". Durante un año más o menos estuvimos en contacto vía teléfono y semanalmente llegaban cartas desde España que sólo tenían una casilla de correos (al irse solo nos dejó $\$ 200.000$ pesos y la promesa de volver). Comenzamos a tener algunos problemas económicos ya que el arriendo era muy caro (por el sector); nos cambiamos a una población, mis hijos comenzaron a pasar hambre ya que debía asumir todos los gastos de una casa y además debía pagar la universidad. (...) [Un día] recibí una carta de este hombre en la cual me pedía dinero porque quería regresar. Obviamente no estaba dispuesta a aquello, tomando en cuenta que ya habían pasado varios años en los cuales jamás mandó un peso para sus hijos, dejándolos en el abandono absoluto, y teniendo presente todos los momentos de penas, necesidades sufridas y luego de haber sentido una decepción por esa persona que había sido tan importante y que ya no lo era, sólo era el padre de los niños, padre que ellos no conocen y por quien no sienten nada, pero a quien exigen en este momento la ayuda que durante 11 años les ha negado.

(Relato escrito entregado por una madre, usuaria de la Oficina Internacional, 27 de noviembre 2012).

(...) Contraje matrimonio... era un matrimonio sólido que se mantuvo 24 años, con dos hijos (...) En el mes noviembre de 2009, una amiga en común (que vivía hace 12 años en Nueva Zelanda) vino a Chile y nos entusiasmó con la idea de que nos fuéramos a ese país, que "estaríamos mejor económicamente y por el futuro de mis hijos". Lo conversamos y mi marido fue primero porque dentro de un mes tendría trabajo y de inmediato me mandaría a buscar con mi hijo menor, pues él se fue con mi hijo mayor en abril del 2010. Pasaron dos meses y la supuesta "amiga" echó a su marido de la casa para convivir con el mío (el 2011 se casaron). Mi hijo regresó porque su padre lo abandonó allá (...) A consecuencia de todo esto, para poder costear los gastos de los pasajes y el viaje, me tuve que endeudar y él ya me había dejado extremadamente endeuda- 
da. Prometió que empezando a trabajar me mandaría el dinero que gasté, pero hasta la fecha no ha mandado nada. Con todos los problemas económicos, yo trabajando esporádicamente con un sueldo bajísimo, tuve que vender la casa "por apuro", súper barata porque me atrasé en los dividendos y se iría a remate, más las otras deudas que aumentaban.

(Relato escrito entregado por una madre, usuaria de la Oficina Internacional, 25 de junio 2012).

Los comportamientos masculinos y paternales descritos por estas madres [mujeres] son posibles de contextualizar a partir de la vigencia que mantiene la ideología patriarcal en el sistema social. En este, operan una serie de imaginarios socioculturales que se fundamentan en la construcción histórica de los géneros y que asocia la feminidad a la maternidad, al "ser madre", en tanto único eje posible para la vida familiar, y la masculinidad a "ser hijo", careciendo de un constructo claro en torno a la figura "ser padre".

Cabe recordar que el hombre era prácticamente polígamo, además se mantenía ausente e itinerante respecto de la vida cotidiana de sus familias, incluso ante cualquier problema escapaba dejando todo en manos de su pareja [madre] (Montecinos, 2007; 48).

Los registros estadísticos de la Oficina Internacional, en su calidad de Autoridad Remitente e Institución Intermediaria para la aplicación del Convenio de Nueva York de 1956, indican que entre el año 2011 y septiembre de 2014 y respecto de un total de 138 solicitudes de pensión alimenticia que:

- Quienes accedieron a esta posibilidad en representación de sus hijos fueron sus madres en un $98 \%$, registrándose sólo un $2 \%$ de solicitantes padres [hombres].

- Las solicitudes de pensiones alimenticias provenientes desde el extranjero alcanzan al 78\% del total de las reclamaciones, mientras que las solicitudes derivadas por Chile hacia otros Estados parte del Convenio alcanzan al 22\% del total de casos. 
- Los Estados/países que concentran el mayor porcentaje de reclamaciones de pensiones alimenticias de parte de Chile son Argentina con un 25\% y España con 18\% respecto del total de peticiones.

\section{Nuevas emergencias: Desafíos}

La sociedad, a través del sistema de Justicia, ha debido integrar las "nuevas formas de hacer familia"; desde el reconocimiento en igualdad de derechos de hijos e hijas nacidos fuera del matrimonio -como un primer hito-, hasta la aprobación del divorcio como mecanismo de disolución del vínculo conyugal que tantos años tardó nuestro país en finalmente aceptar (10 años). Ambos ejemplos corresponden a cambios sociales de tipo familiar, los que al estabilizarse o arraigarse en el sistema social, finalmente deberán ser integrados por el sistema jurídico en la regulación de las relaciones de familia.

Desde esa lógica, constituye un desafío la integración de fenómenos ya asentados en nuestro país como resulta el fenómeno migratorio. Al respecto, Chile se ha situado en la región como un país receptor para este conglomerado social (migrantes) y según los datos de la encuesta CASEN 2013, las cifras se han duplicado conforme a la medición efectuada el año 2006, existiendo al menos 354.81 personas en situación de migración, cifra que representa el $2,1 \%$ del total de la población residente en el país.

Al considerar el país de origen de dicho conglomerado social, este proviene mayoritariamente de Perú (33,3\%), Argentina (15\%) y Colombia (13\%), población que se ha concentrado en la Región Metropolitana (66,4\%). En términos de género y edades, destaca que la mayoría de la población migrante corresponde a mujeres $(55,1 \%)$ y el rango etario oscila entre los 30 y 44 años para ambos sexos $(33,6 \%)$, quienes -conforme a la citada encuesta y en un porcentaje superior al 50\%- residen en "hogares nucleares biparentales".

Los incipientes datos sociodemográficos expuestos, indicarían que el conglomerado migrante, al menos en Chile, es un grupo 
que pretende y aspira -más allá de las perspectivas socioeconómicas que pudiese implicar el cambio de país de residencia- a construir y proyectar una vida íntima en familia, con una conformación bastante tradicional/clásica, propia al imaginario social de lo que se comprende en la región por "familia" y consecuente a la ideología patriarcal que la sustenta. Sin embargo, permanecen en situación de invisibilidad los riesgos que se enfrentan ante la eventual separación de la pareja de padres y respecto de familias con características de transnacionalidad $\left({ }_{¿}\right.$ Desearé retornar a mi país de origen?, ¿Quién se responsabilizará de los hijos en común?, ¿Cómo se concretará el contacto de los hijos con el otro padre o madre?, entre otras consideraciones).

A partir de lo expuesto, es necesario reflexionar en torno al imaginario que radica el cuidado de los hijos exclusivamente en sus madres [mujeres], reconociendo que los padres [hombres] también desean, son capaces y necesitan vincularse profundamente con sus hijos. En definitiva, resulta necesario abandonar las construcciones estereotipadas que se han integrado en torno al género y la parentalidad, integrando y dirigiendo políticas públicas también hacia el conglomerado padre-masculino.

No hay políticas públicas dirigidas a hombres, porque hay estudios que indican que no hay posibilidades de tratamiento exitoso con ellos, y como los recursos son escasos, se considera mejor invertirlos en mujeres o en otros conglomerados. Personalmente no estoy de acuerdo, creo que las intervenciones culturales, más que las terapéuticas, son las adecuadas (Olavarría, Seminario de Masculinidades y Políticas Públicas: Involucrando a hombres en la equidad de género, Universidad de Chile, agosto 3, 2009)

Con el mismo énfasis, debemos ser capaces de integrar que hijos e hijas, niños y niñas, no son "propiedad" de sus padres y madres [de los adultos], pues son efectivamente sujetos de derecho y, por lo tanto, se debe respetar no sólo sus cuerpos y sus afectos (a propósito de la violencia sexual, física y emocional que muchos de 
ellos/as vivencian en lo cotidiano), sino también, sus vínculos sociales, su "lugar" de residencia, sus pertenencias, en definitiva, todo lo que forma parte de su identidad y particularidad.

Finalmente integrar que las familias, para ser concebidas como tales, no requieren de una espacialidad común y cotidiana, existen vínculos profundos que van más allá del compartir una vivienda, incluso un mismo territorio, dimensión desde donde es posible concebir las familias, las maternidades y parentalidades de tipo transnacional ${ }^{4}$.

(...) A pesar de la distancia, diversos estudios demuestran que las familias persisten como institución adaptándose a la nueva realidad y buscando nuevas formas de mantener y fortalecer los vínculos familiares (tanto económicos como afectivos y de gestión del cuidado) en una nueva estructura transnacional (...) Lo que constituye una novedad respecto de épocas anteriores, es la posibilidad material que ofrecen los avances en las nuevas tecnologías, los sistemas de transporte y las comunicaciones de permitir formas de relaciones sociales que faciliten a las unidades familiares "transnacionales" seguir actuando como una familia (...) Además el contacto frecuente también posibilita que se pueda aligerar el costo emocional de la separación (Parella, 2007;156-159).

A partir del siguiente relato, que corresponde a una mujer-madremigrante, es posible observar cómo se configuran en su experiencia, varios de los puntos expuestos en el presente artículo y cómo logra ejercer, durante varios años, una maternidad de tipo transnacional:

(...) La relación entre nosotros comenzó en el 2004, en Casa Grande, Provincia de Ascope. Yo tenía 17 años y él 24. Pololeamos poco tiempo, cuando a unos meses me di cuenta que estaba embarazada (...) En septiembre del 2005 el papá de mi

Se caracterizan por la dispersión constante de sus miembros en distintos países debido a la migración de uno o más de sus integrantes, lo que implica una separación física y geográfica de sus miembros durante prolongados periodos. 
hijo viajó a Argentina, supuestamente a buscar mejoras para nosotros. Cuando estuvo allá él empezó mandándome dinero, dejando de enviarme un mes o cuando no le alcanzaba. Yo decidí viajar a Chile, donde tenía apoyo de mi padre y de mi hermana mayor. Viajé en agosto del 2006 cuando mi hijo tenía 10 meses de vida... vine a buscar un mejor futuro y dejé a mi hijo al cuidado de mi madre, quien se encontraba en Perú. En septiembre del 2006 empecé a trabajar y desde ese día giré dinero para mi hijo (para entonces la relación con el padre ya no era la misma, él seguía girando la misma cantidad de dinero $-\$ 30$ a $\$ 60$ dólares al mes- y yo decidí llamarlo y conversar para ver si la relación se retomaba y luchábamos juntos por nuestro hijo. En septiembre del 2007 él viajo a Chile y vivimos en la casa de mi padre, quisimos retomar la relación pero, por mi parte, ya no sentía lo mismo, por parte de él no lo sé. Mensualmente le girábamos dinero a nuestro hijo, quien seguía al cuidado de mi madre. Al poco tiempo conocí a un joven, empezamos a conocernos y lamentablemente yo me enamoré, entonces decidimos cortar la relación con el padre de mi hijo y él regresó a Argentina, eso fue en septiembre del 2008. Después de eso nosotros ya no pudimos sostener una conversación entre ambos como gente madura, así que él decidió tratar cualquier tema que correspondiera al niño directamente con mi madre. Yo seguí enviándole dinero a mi madre para mi hijo, siempre lo llamaba, hablaba con él constantemente, nunca me despreocupé de mi hijo (...) Mi madre me comentaba que el padre de mi hijo mandaba dinero sólo cuando él podía, que no era una mensualidad fija (yo enviaba $\$ 100$ dólares mensuales y, a veces, $\$ 120$ dólares). El padre de mi hijo tampoco llamaba para saber de su hijo. En febrero del 2011 decidimos encontrarnos en Perú para bautizar a nuestro hijo que ya tenía 5 años. En esa oportunidad conversamos como adultos y tomamos la decisión que el niño vendría conmigo a Chile, puesto que él también tenía su vida hecha en Argentina y no podía cuidar del niño (aparte la idea era que estuviera conmigo que soy la mamá). Tampoco quería 
que se separara de mi madre ya que ella lo había criado desde pequeño y al separarlos él sufriría mucho (...) En abril del 2012 mi padre viajó a Perú y de vuelta trajo a mi madre, a mis hermanos y a mi hijo. El niño viajó con el permiso de su papá que, aunque tuve que esperar mucho tiempo para conseguirlo, al final se pudo (...) El padre de mi hijo desde el 07 de diciembre del 2011 que no envía dinero y tampoco se comunica.

(Relato escrito entregado por una madre, usuaria de la Oficina Internacional, 22 de febrero 2013).

Este tipo de maternidades integra muchas veces sentimientos de culpa, frustración, ambivalencia:

Son mujeres que viven con tristeza la distancia con sus hijos que están en su país de origen. Pero también hay casos que han sido visibilizados en el trabajo de campo, que no desean la reagrupación pues valoran la vida que mantienen sus hijos en sus países de origen y no tener que someterlos a los sacrificios que en ocasiones implica la migración (González, Seminario Clínico de Migración y Diversidad Familiar, Maternidades Transnacionales, Universidad Católica Silva Henríquez y Universidad Alberto Hurtado, diciembre 4, 5 y 6, 2012).

En síntesis, se torna fundamental que profesionales de las Ciencias Sociales ampliemos nuestra capacidad de observación respecto a las relaciones de familia; los desempeños conforme a los géneros; la parentalidad y las edades, a fin de reconfigurar y actualizar dichas distinciones dejando atrás desigualdades y/o asimetrías con las que hasta ahora dichas perspectivas han operado.

\section{Bibliografía:}

Acta final de la conferencia de Naciones Unidas sobre obligación de dar alimentos, hecha en Nueva York el 20 de junio de 1956. Convenio de Nueva York. Disponible en: http://www.hcch.net/index_es.php?act=publications. details\&pid $=4162 \& d t i d=45$ [Fecha de acceso: Agosto13, 2015]

Asamblea de Naciones Unidas del 20 de noviembre de 1989. Convención Internacional sobre los Derechos del Niño. Disponible en: 
http://www.unicef.cl/unicef/index.php/texto-oficial-dela-convencion [Fecha de acceso: Agosto13, 2015]

Biblioteca del Congreso Nacional. Código Civil. Disponible en: http:// www.leychile.cl/Navegar?idNorma $=172986$ [Fecha de acceso: Agosto 13, 2015]

Carrillo, E. (2011). Niños y niñas involucrados en procesos de sustracción familiar en México. Revista Latinoamericana de Ciencias Sociales, Niñez y Juventud, 2 (9), pp. 561-572. Disponible en: http://www.redalyc.org/pdf/773/77321592006.pdf [Fecha de acceso: Agosto13, 2015]

Conferencia de La Haya de Derecho Internacional Privado. Convenio sobre los Aspectos Civiles de la Sustracción Internacional de Menores. Disponible en: http://www.hcch.net/index_ es.php?act=conventions.text\&cid=24 [Fecha de acceso: Agosto 13, 2015]

Conferencia de Ministros de Justicia de los Países Iberoamericanos (2012). Estadística e Indicadores Armonizados de los Sistemas de Justicia de América Latina. Disponible en: http:// www.comjib.org/estadisticas_indicadores [Fecha de acceso: Agosto 13, 2015]

Corporación de Asistencia Judicial de la Región Metropolitana. Disponible en: http://www.cajmetro.cl/justicia-te-ayuda/ [Fecha de acceso: Agosto 13, 2015]

Corporación de Asistencia Judicial de Valparaíso. Disponible en: http:// www.cajval.cl/ [Fecha de acceso: Agosto 13, 2015]

Corporación de Asistencia Judicial de Tarapacá. Disponible en: http:// www.cajta.cl/ [Fecha de acceso: Agosto 13, 2015]

Corporación de Asistencia Judicial del Biobío. Disponible en: http:// www.cajbiobio.cl/ [Fecha de acceso: Agosto 13, 2015]

Ministerio de Desarrollo Social - Gobierno de Chile. Disponible en: http://observatorio.ministeriodesarrollosocial.gob.cl/casen/casen-documentos.php?c=118 [Fecha de acceso: Octubre 02, 2015]

Montecinos, S. (2007). Madres y Huachos. Alegorías al Mestizaje Chileno (4a. ed.) Editorial Catalonia, Colección Dos Siglos Bicentenario de Chile, Santiago, Chile.

Parella, S. (2007). Los vínculos afectivos y de cuidado en las familias transnacionales: Migrantes ecuatorianos y peruanos en España. Migraciones internacionales, 4(2), 151-188. Disponible en: http://www.scielo.org.mx/scielo.php?script=sci_ arttext\&pid=S1665-89062007000200006\&lng=es\&tlng= es [Fecha de acceso: Agosto 13, 2015] 